\title{
Post-Marketing Surveillance of Quality of Artemether Injection Marketed in Southwest Nigeria
}

\author{
Ibrahim A. Hassan, ${ }^{1}$ Adebanjo J. Adegbola, ${ }^{2 \star}$ Julius O. Soyinka, ${ }^{2}$ Cyprian O. Onyeji, ${ }^{2,3}$ and Oluseye O. Bolaji \\ ${ }^{1}$ Department of Pharmacy, Obafemi Awolowo University Teaching Hospital Complex, Ile-Ife, Nigeria; ${ }^{2}$ Department of Pharmaceutical Chemistry, \\ Obafemi Awolowo University, Ile Ife, Nigeria; ${ }^{3}$ Department of Pharmaceutical and Medicinal Chemistry, University of Nigeria, Nsukka, Nigeria
}

\begin{abstract}
Access to good-quality medicines remains a contentious issue in developing countries. This development is worrisome, particularly in a setting with a high incidence of malaria. Monitoring of antimalarial drugs in the commercial domain becomes necessary; thus, we evaluated the quality of artemether injection marketed in Southwest Nigeria. A cross-sectional survey was conducted to obtain 22 different brands of artemether injections within Southwest Nigeria. The samples were examined for their sources, lot numbers, containers for injection, oil base used for preparation, and dates of expiration. Further analysis involved visual inspection, assessment of extractable volume, identity tests, and an assay of active pharmaceutical ingredient. The pharmaceutical quality of each sample was determined according to the criteria set in the International Pharmacopoeia 2019. None of the products had any particulate matter, but there were certain irregularities in their presentation. Eighteen of the 22 products $(81.7 \%)$ were packaged in plain instead of ambercolored ampoules, and $77.3 \%(17 / 22)$ did not indicate the oil base used as the vehicle on the label as against the pharmacopoeial standard. Sixteen products (72.7\%) passed the extractable volume test, although the remaining $22.3 \%$ did not conform to the extractable volume per unit dose. Artemether was present in all the samples, although only $40.9 \%$ $(9 / 22)$ met the recommended percentage content of $90-110 \%$ of artemether. The study revealed the presence of a high percentage of substandard artemether injection products marketed in Nigeria. Further surveillance is warranted to confirm the quality of artemether injection circulated in other regions within Nigeria.
\end{abstract}

\section{INTRODUCTION}

Artemether-lumefantrine is now a preferred agent in major treatment guidelines and a first choice for Plasmodium falciparum malaria, whereas artesunate injection is preferred for the treatment of severe malaria. ${ }^{1}$ However, artemether, given intramuscularly, is a backup for severe malaria and a treatment option for patients with vomiting. ${ }^{1,2}$ Artemether is an oilsoluble derivative of artemisinin $\left(\mathrm{C}_{16} \mathrm{H}_{26} \mathrm{O}_{5}\right.$, Figure 1), and the molecule is known to play a critical role in the bid to alleviate the threat of malaria. Malaria contributes significantly to global health and economic burden, as the morbidity and mortality of the disease persist at unacceptable levels, especially in subSaharan African and Southeast Asian countries. ${ }^{3,4}$ The global trend in the burden of malaria cases has shown that the scourge of malaria remains prominent among pregnant women and young children in Africa. ${ }^{5}$ Nigeria carries the most substantial burden of the disease as the country records more cases and deaths from malaria than any country the world over. $^{6}$ Malaria is also the leading cause of death in Nigeria. ${ }^{5-7}$ At present, the country accounts for about $25 \%$ of the 228 million global cases of malaria and $24 \%$ of 405,000 deaths, with significant maternal and child health consequences. ${ }^{5}$ Rapid progression of uncomplicated malaria to severe cases has been associated with the high mortality rate recorded in children younger than five years.

Along with the adoption of artemisinin-based combination therapies (ACTs) for antimalarial treatment, the use of parenteral quinine or artemisinin derivatives in severe malaria cases in Nigeria had also been recommended by the National Malaria Strategic Plan in alignment with the recommendations from the WHO. ${ }^{8}$ Intravenous artesunate, intramuscular artemether, and quinine injections are the recommended first-line

*Address correspondence to Adebanjo J. Adegbola, Department of Pharmaceutical Chemistry, Faculty of Pharmacy, Obafemi Awolowo University, Ile Ife, 220282 Osun state, Nigeria. E-mail: adegbolaaj@ oauife.edu.ng drugs in the treatment of severe malaria. ${ }^{1,9}$ However, artesunate is prohibitively expensive and scarcely available in the remote areas across Nigeria. Artemether is an immediate replacement for the artesunate injection in circumstances where the latter is unavailable. $^{10-12}$ It is more effective than quinine in preventing death associated with severe malaria ${ }^{10}$ and is found to be useful in the treatment of uncomplicated malaria in patients who cannot tolerate oral regimen. ${ }^{1,10-15}$ Artemether is presented as a premixed lipid-based formulation for intramuscular use. It is in the Essential Drug List and widely available in many African nations. ${ }^{16}$ As a result, various generic brands of artemether injection are licensed for distribution in Nigeria.

Antimalarial drugs are essential weapons for the achievement of malaria treatment goals. ${ }^{17-19}$ But, the global drug distribution landscape is repeatedly challenged with the circulation and inadvertent use of poor-quality medicines. ${ }^{20}$ Unfortunately, poor-quality antimalarial drugs are often associated with a high rate of malaria treatment failure and poor health outcomes, as reported in many surveys. ${ }^{21-24}$ Of additional interest is the scourge of development of antimalarial resistance, which has been correlated with the use of substandard antimalarial medicine..$^{20,22,23}$ In a survey by Hajjou et al., ${ }^{25}$ antimalarial drugs were found to represent $52.5 \%$ of all substandard medicines and $92.6 \%$ of all falsified drugs detected. $^{25}$ The previous report revealed that Nigeria is one of the worst-hit countries with drug falsification crimes. ${ }^{26}$ Substandard medicines are out-of-specification products. They are genuine and authorized medicines that fail to meet the quality standards or specifications that the producer says they meet. ${ }^{27}$ It may arise from manufacturing errors or degradation of finished products. Whereas for falsified medicine products, the aim is to deliberately or fraudulently misrepresent the identity, composition, or source of a brand name. They include "products with the correct ingredients or with the wrong ingredients, without active ingredients, with an insufficient active ingredient, or with fake packaging." 27,28

Over the last decade, several surveys and investigational studies have been conducted within different regions of 


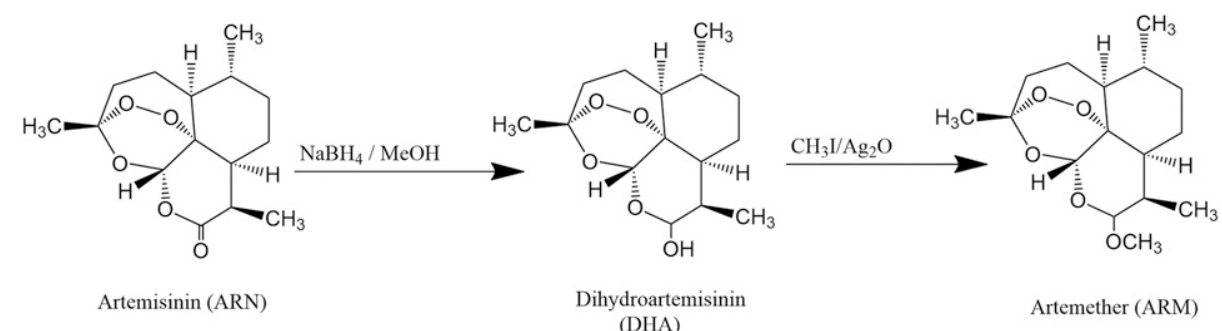

FIGURE 1. Artemisinin and derivatives.

Nigeria to evaluate the quality of marketed antimalarial drug products. These studies have provided some evidence for the presence of substandard antimalarial drugs in circulation within the Southeast, ${ }^{29,30}$ South-south, ${ }^{31}$ and Southwest ${ }^{32-34}$ Nigeria. However, most of these surveys focused on oral formulations. At present, there is a lack of information on the quality of parenteral antimalarial medicines marketed in the country. Recognizing the importance of parenteral formulations to malaria treatment, this study aimed to assess the quality of artemether injection products sold in Nigeria, with emphasis on the southwestern part of the country.

\section{MATERIAL AND METHODS}

Chemical and reagent. The artemether reference standard (RS) with a purity of $98 \%$ was obtained from AK Scientific, Inc. (Union City, CA) with a catalog number 71963-77-4. Highperformance liquid chromatography (HPLC)-grade Honeywell ${ }^{\circledR}$ acetonitrile was from Fisher Scientific Ltd (Loughborough, United Kingdom), and analytical-grade isopropyl alcohol was from Hopkins \& Williams (London, England). Sulfuric acid $98 \%$, vanillin, and absolute alcohol were obtained from Sanjay Chemicals Ltd. (Mumbai, India). All artemether injection samples were purchased from licensed pharmacies within Southwest Nigeria.

Instrument. The high-performance liquid chromatographic system consisted of an Agilent 1100 system (Palo Alto, CA) using a quaternary pump fitted with a Rheodyne model 7725 valve (Rohnert Park, CA), a $150 \times 4.6 \mathrm{~mm} \times 5 \mu \mathrm{m}$ Zorbax $\mathrm{C}_{18}$ column, a diode array detector (DAD), and HP ChemStation software. An adjustable micropipette from Invitro Biotech Ltd (Hyderabad, India), a Vortex mixer from Gallenkamp (London, United Kingdom), and an analytical weighing balance (Mettler Toledo, Columbus, $\mathrm{OH}$ ) were also used.

Location of the survey. The survey was carried out in the southwestern area of Nigeria, a geopolitical zone consisting of six states: Ekiti, Osun, Oyo, Ogun, Ondo, and Lagos states (Figure 2). The region lies between longitude $2^{\circ} 31^{\prime}$ and $6^{\circ} 00^{\prime} \mathrm{E}$ and latitude $6^{\circ} 21^{\prime}$ and $8^{\circ} 37^{\prime} \mathrm{N}$ with a total land area of $77,818 \mathrm{~km}^{2}$ and an estimated population of $38,257,300$ people. ${ }^{35,36}$ The states within this region house several indigenous pharmaceutical industries, many of which operate secondary and tertiary manufacturing plants. Numerous licensed wholesale and retail pharmaceutical outlets also abound in this zone, with an active trade system with other parts of the country.

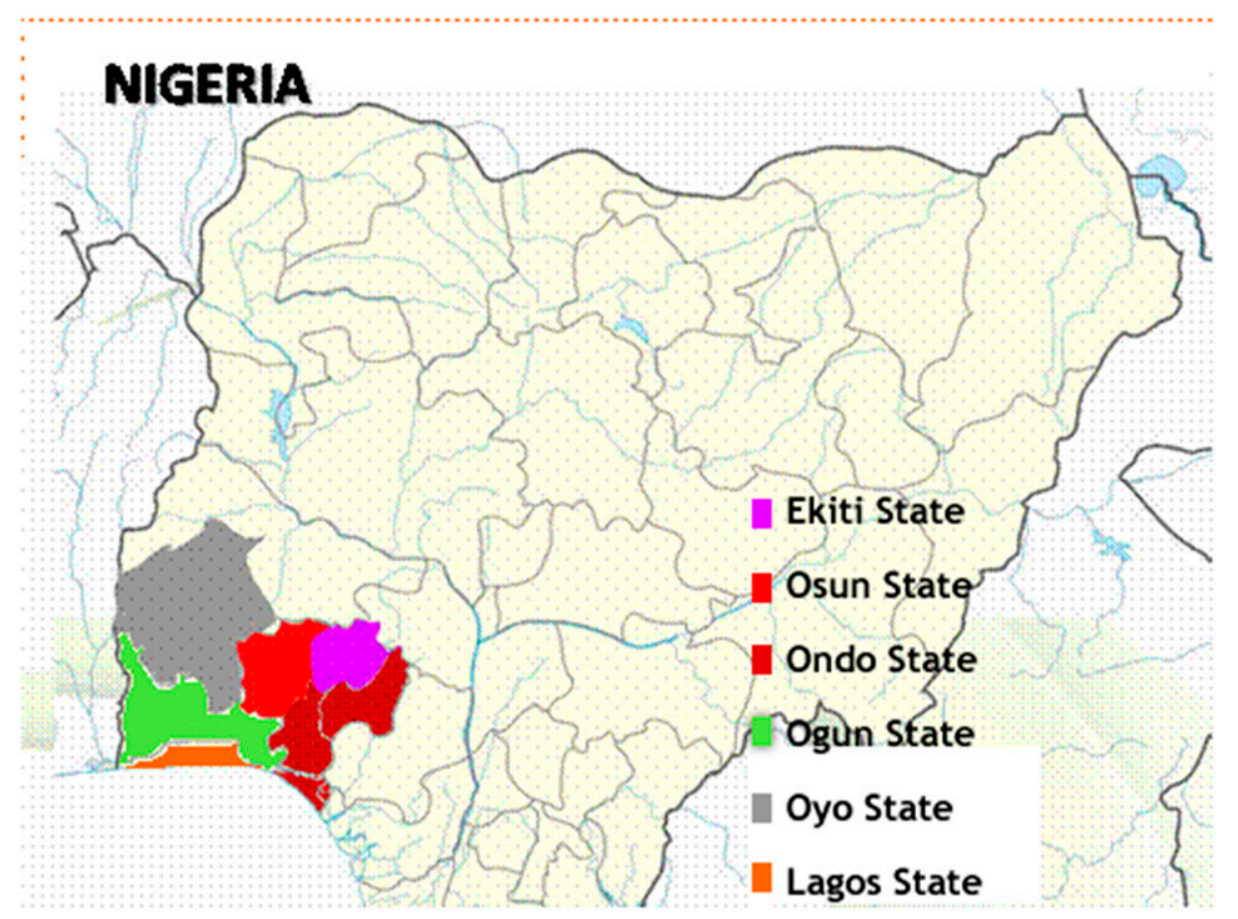

FIGURE 2. Map showing Southwestern Nigeria for the study survey. This figure appears in color at www.ajtmh.org. 
Sampling. The sample collection and sampling strategy focused on the estimation of the percentage of poor-quality artemether injection products within the study location. ${ }^{28}$ The equation for estimating the sample size of a finite population was adopted for sample size determination. ${ }^{37}$ The total number $(N)$ of artemether injection products registered in Nigeria was considered to be 38 , the prevalence of substandard and falsified antimalarial in low-to-medium-income settings from previous studies was taken as $19.1 \%$, and the margin of error and confidence level were assumed to be $10 \%$ and $95 \%$, respectively. The sample size was estimated as 24 products. Artemether injection products were obtained from five retail and five wholesale pharmacies per each state within Southwest Nigeria using a convenience sampling technique. During the survey, 22 different products were found and collected between May 2019 and August 2019 by mystery shoppers. Information including the date of purchase, place of purchase, manufacturer's address, product batch information, and manufacturing and expiry dates of the products were documented. The samples were stored at $4^{\circ} \mathrm{C}$ until analysis within 2 months of the collection.

Preliminary analytical procedure. The samples were analyzed according to the methods specified in the monograph for artemether injection in the eighth edition of the International Pharmacopoeia (Int. Ph.) 2019. ${ }^{38}$ The investigated samples were assigned identification codes for makeshift identity from A001 to A022.

Visual inspection. The injections were examined for the presence of particulate matter, by viewing the content of each ampoule in daylight illumination, after a gentle shaking for 30 seconds. The product packaging information, including name, strength, batch and license codes, type of oil used, and ampoule properties, were also checked and recorded.

Extractable volume of parenteral preparation. The volume of artemether injection extractable from a single ampoule using a $2-\mathrm{mL}$ syringe with a $21 \mathrm{G}$ needle was recorded. The total volume of injection from three (3) randomly picked ampoules from a pack of 10 was also determined by bulking the contents in a $10-\mathrm{mL}$ measuring cylinder, and the final volume was noted.

Identity test for artemether. According to the Int. Ph. 2019, a 0.4-mL aliquot from a 1-mL ampoule of the investigated injection was pipetted into a test tube. Then, $6 \mathrm{~mL}$ of absolute (dehydrated) ethanol was added, and the content was thoroughly mixed by gently shaking. Two drops of the mixture were then placed on a white porcelain dish, and a drop of vanillin/sulfuric acid test solution 1 (TS1) was added. The color formation was observed and recorded.

Assay procedure. Preparation of sample and stock solution. Artemether RS (80 mg) was weighed into a 10-mL volumetric flask and dissolved with acetonitrile to make an 8 $\mathrm{mg} / \mathrm{mL}$ solution. The content was sonicated for 20 minutes. Seven other calibration standards were made from the stock solution via serial dilution. For the investigated samples, six ampoules of each sample were bulked together and vortexmixed for 1 minute. Then, $1 \mathrm{~mL}$ of each sample was pipetted into a $10-\mathrm{mL}$ volumetric flask and made up to $10 \mathrm{~mL}$ with the mobile phase, acetonitrile:water (62:38\% v/v). This procedure was conducted in three replicates. The content was vortexmixed for 2 minutes, and $100 \mu \mathrm{L}$ aliquot was pipetted into a sample tube. The solution was further diluted with the mobile phase to make a final solution of $800 \mu \mathrm{g} / \mathrm{mL}$ as the nominal strength.
HPLC assay. This was carried out according to the monograph specifications (Int. Ph. 2019) ${ }^{38}$ for quantification of the active pharmaceutical ingredient (API) in artemether injection. Chromatographic condition consisted of $62 \%$ acetonitrile and $38 \%$ water through a $150 \times 4.6 \mathrm{~mm} \times 5 \mu \mathrm{m}$ Zorbax $\mathrm{C}_{18}$ column using a flow rate of $1.5 \mathrm{~mL} / \mathrm{min}$ in an isocratic mode. And then, $20 \mu \mathrm{L}$ of each standard solution of artemether and that of each of the investigated samples were chromatographed onto the column, and the response was detected using a DAD programmed at $216 \mathrm{~nm}$ throughout a 6-minute run time. A standard calibration curve was prepared for the artemether RS solution via serial dilution within a concentration range of $40-8,000 \mu \mathrm{g} / \mathrm{mL}$. Linearity was assessed by plotting the peak areas versus the calibrated standard using the weighted average of the responses from three replicates. The maximum allowed deviation for each calibration standard was set at $\leq 15 \%$, except for the lowest point set at $\leq 20 \%$. The intraand inter-day accuracy and precision were conducted according to Food and Drug Administration (FDA) guidelines ${ }^{39}$

\section{RESULTS}

Description of the product presentation. Twenty-two products were found within the study territory corresponding to $58 \%$ of the artemether injection products registered by the National Agency for Food and Drug Administration and Control (NAFDAC). All the samples came in packs of $1 \mathrm{~mL} \times 6$ ampoules, and each ampoule was stated to contain $80 \mathrm{mg} / \mathrm{mL}$ of artemether. The sample information containing the details of identification and packaging are provided in Table 1, with 19 of the products being imported from China, whereas the remaining three originated from India.

Further visual inspection showed that the products contained no visible particulate matter. However, 18 products (81.8\%) were presented in clear glass ampoules, and only four products $(18.2 \%)$ declared the vehicle used for the injectable formulation. Table 2 shows the details of the extractable volume analysis. The extractable volumes in six products (27.3\%) were significantly less than the expected extracted volume of $3 \mathrm{~mL}$ from 3 ampoules.

Identity for API. All samples produced a bright red coloration to the vanillin/sulfuric acid test, indicating the presence of artemether in all the products. A comparison of the retention time (2.7 minutes) from the HPLC chromatogram (Figure 3) for the $\mathrm{RS}$ of artemether with that of the investigated products confirmed that all the samples contained the API stated on the label.

Assay for API. The intra-day and inter-day percentage variability in the accuracy of the assay ranged from $1.28 \%$ to $14.4 \%$, and precision was within $1.78-5.98 \%$. Bias in accuracy and precision was within an acceptable deviation of $\leq 15 \%$ according to FDA guidelines. ${ }^{39}$ Table 3 shows the determined contents of artemether in triplicate analysis for each product. A graphical presentation of the percentage of contents for artemether products is shown in Figure 4.

\section{DISCUSSION}

Artemether injection product needs to comply with both the general specifications for parenteral preparations and other quality criteria specific for the product before it can be accepted to be of good quality. First, artemether injection should be packaged in a final container that offers adequate 
TABLE 1

Details of product samples

\begin{tabular}{|c|c|c|c|c|c|c|c|}
\hline Product code & Batch number & Date of manufacture & Date of expiry & Place of manufacture & Ampoule color & Oil-based & Pack size \\
\hline A001 & 170713 & July 2017 & July 2020 & China & Transparent & Not stated & $80 \mathrm{mg} / 1 \mathrm{~mL} \times 6$ ampoules \\
\hline A002 & 181025 & October 2018 & October 2021 & China & Transparent & Not stated & $80 \mathrm{mg} / 1 \mathrm{~mL} \times 6$ ampoules \\
\hline A003 & 171112 & November 2017 & November 2020 & China & Transparent & Not stated & $80 \mathrm{mg} / 1 \mathrm{~mL} \times 6$ ampoules \\
\hline A004 & 170111 & January 2017 & January 2020 & China & Transparent & Not stated & $80 \mathrm{mg} / 1 \mathrm{~mL} \times 6$ ampoules \\
\hline A005 & 180717 & July 2018 & July 2021 & China & Amber & Not stated & $80 \mathrm{mg} / 1 \mathrm{~mL} \times 6$ ampoules \\
\hline A006 & 180711 & July 2018 & July 2021 & China & Transparent & Not stated & $80 \mathrm{mg} / 1 \mathrm{~mL} \times 6$ ampoules \\
\hline A007 & 180108 & January 2018 & January 2021 & China & Transparent & Not stated & $80 \mathrm{mg} / 1 \mathrm{~mL} \times 6$ ampoules \\
\hline A008 & 181140 & November 2018 & November 2021 & China & Transparent & Tea seed Oil & $80 \mathrm{mg} / 1 \mathrm{~mL} \times 6$ ampoules \\
\hline A009 & 1801013 & January 2018 & January 2021 & China & Transparent & Not stated & $80 \mathrm{mg} / 1 \mathrm{~mL} \times 6$ ampoules \\
\hline A010 & 180324 & March 2018 & March 2021 & China & Transparent & Not stated & $80 \mathrm{mg} / 1 \mathrm{~mL} \times 6$ ampoules \\
\hline A011 & 161101 & November 2016 & November 2019 & China & Amber & Not stated & $80 \mathrm{mg} / 1 \mathrm{~mL} \times 6$ ampoules \\
\hline A012 & 170807 & August 2017 & August 2020 & China & Amber & Not stated & $80 \mathrm{mg} / 1 \mathrm{~mL} \times 6$ ampoules \\
\hline A013 & 20171202 & December 2017 & December 2020 & China & Transparent & Not stated & $80 \mathrm{mg} / 1 \mathrm{~mL} \times 6$ ampoules \\
\hline $\mathrm{A} 014$ & BEA06196 & July 2018 & June 2021 & India & Transparent & Coconut oil & $80 \mathrm{mg} / 1 \mathrm{~mL} \times 6$ ampoules \\
\hline $\mathrm{A} 015$ & 1704125 & April 2017 & April 2020 & China & Transparent & Not stated & $80 \mathrm{mg} / 1 \mathrm{~mL} \times 6$ ampoules \\
\hline A016 & 170828 & August 2017 & August 2020 & China & Transparent & Not stated & $80 \mathrm{mg} / 1 \mathrm{~mL} \times 6$ ampoules \\
\hline A017 & $1635 k 1607$ & October 2016 & September 2019 & India & Transparent & Arachis Oil & $80 \mathrm{mg} / 1 \mathrm{~mL} \times 6$ ampoules \\
\hline A018 & 170715 & July 2017 & July 2020 & China & Transparent & Not stated & $80 \mathrm{mg} / 1 \mathrm{~mL} \times 6$ ampoules \\
\hline A019 & ET8005 & February 2018 & January 2021 & India & Amber & Ethyl oleate B.P & $80 \mathrm{mg} / 1 \mathrm{~mL} \times 6$ ampoules \\
\hline A020 & 60,273 & August 2017 & April 2020 & India & Transparent & Not stated & $80 \mathrm{mg} / 1 \mathrm{~mL} \times 6$ ampoules \\
\hline $\mathrm{A} 021$ & 180311 & August 2018 & August 2021 & China & Transparent & Not stated & $80 \mathrm{mg} / 1 \mathrm{~mL} \times 6$ ampoules \\
\hline A022 & $1568 \mathrm{H} 1703$ & August 2017 & July 2020 & India & Transparent & Arachis oil & $80 \mathrm{mg} / 1 \mathrm{~mL} \times 6$ ampoules \\
\hline
\end{tabular}

protection from light, such as an amber-colored ampoule. ${ }^{38}$ Besides, the oil base, used as a vehicle, in the formulation should be stated in the label for each product. ${ }^{38}$ The information on the oil base is essential because the recommended HPLC method to check the presence of related substances may not be suitable if Arachis oil is present in the formulation. ${ }^{38}$

On the contrary, the majority of the samples analyzed were presented in plain ampoules, although approximately $81.8 \%$ of the samples did not disclose the oil base used for the formulation. Nonconformity with the standard requirement, as per packaging, is considered a significant oversight considering that artemisinin derivatives are photoreactive because

TABLE 2

Result for extractable volume of injection

\begin{tabular}{lcccc}
\hline & \multicolumn{4}{c}{ Volume of injection extractable $(\mathrm{mL})$} \\
\cline { 2 - 5 } Product code & 1st & 2nd & 3rd & Total volume \\
\hline A001 & 1.1 & 0.9 & 0.9 & 3.0 \\
A002 & 0.9 & 1.0 & 0.9 & 3.1 \\
A003 & 0.9 & 1.0 & 1.0 & 3.1 \\
A004 & 0.9 & 1.0 & 0.9 & 3.0 \\
A005 & 0.9 & 0.9 & 0.9 & 3.0 \\
A006 & 0.9 & 1.0 & 1.0 & 2.9 \\
A007 & 0.9 & 0.7 & 0.8 & 2.8 \\
A008 & 0.9 & 0.7 & 0.7 & 2.8 \\
A009 & 0.8 & 0.9 & 0.9 & 2.9 \\
A010 & 0.9 & 1.0 & 0.9 & 3.2 \\
A011 & 0.9 & 1.0 & 0.9 & 3.1 \\
A012 & 0.9 & 0.9 & 1.0 & 3.0 \\
A013 & 1.0 & 1.0 & 0.9 & 3.1 \\
A014 & 0.9 & 0.9 & 1.1 & 3.0 \\
A015 & 0.8 & 1.1 & 0.9 & 3.1 \\
A016 & 0.9 & 1.0 & 0.9 & 3.2 \\
A017 & 0.9 & 0.9 & 0.9 & 2.9 \\
A018 & 0.8 & 0.8 & 0.8 & 2.8 \\
A019 & 1.0 & 1.0 & 1.0 & 3.2 \\
A020 & 0.9 & 1.0 & 1.0 & 3.1 \\
A021 & 1.0 & 1.0 & 1.1 & 3.1 \\
A022 & 0.9 & 1.1 & 1.0 & 3.0 \\
\hline
\end{tabular}

they contain a labile sesquiterpene ring with an endoperoxide bridge. ${ }^{40}$ The presence of this moiety suggests that artemether injection stored in a clear transparent ampoule has the potential to undergo photodegradation, resulting in a product with less antiplasmodial activity and possible toxicity. ${ }^{40} \mathrm{An}$ alert has been raised to NAFDAC regarding this observation. Besides, a shortcoming in the extractable volume from each ampoule was found in $27.3 \%$ of the investigated products. This finding suggests the possibility of inadequate adherence to Good Manufacturing Practice. Nonconformity with the requirement for extractable volume analysis indicates that accurate dosing may not be attainable while administering the artemether injection products analyzed. It is expected that a single dose injection should contain an overage in volume above the content indicated on the label to allow for withdrawing of accurate doses during administration. ${ }^{41}$ Inconsistency in the dose of artemether administered arising from a lower extractable volume may consequentially warrant a poor treatment outcome. The subtherapeutic dose is of great concern considering the emergence of resistance to the artemisinin-based regimen in some regions across the globe, particularly in Southeast Asia, where most of these products were manufactured. ${ }^{42,43}$

The identity tests confirmed that the investigated products did contain the right API, artemether. However, our findings regarding the amount of the API are worrisome as only $40.9 \%$ of the investigated samples met the requirement for the content assay set in IP 2019. The official standard recommends that "artemether injection should contain not less than $90.0 \%$ and not more than $110.0 \%$ of the amount of $\mathrm{C}_{16} \mathrm{H}_{26} \mathrm{O}_{5}$ stated on the label." The results of the content analysis of API suggest that the dose units of most of the investigated products contain insufficient levels of artemether. The substandard artemether injection is suggested to have arisen from the use of the inappropriate final container as artemisinin derivatives are inherently prone to photodegradation on exposure to light. The reduced amount of artemether could contribute a higher risk of reduced efficacy, treatment failure, delayed parasite clearance 

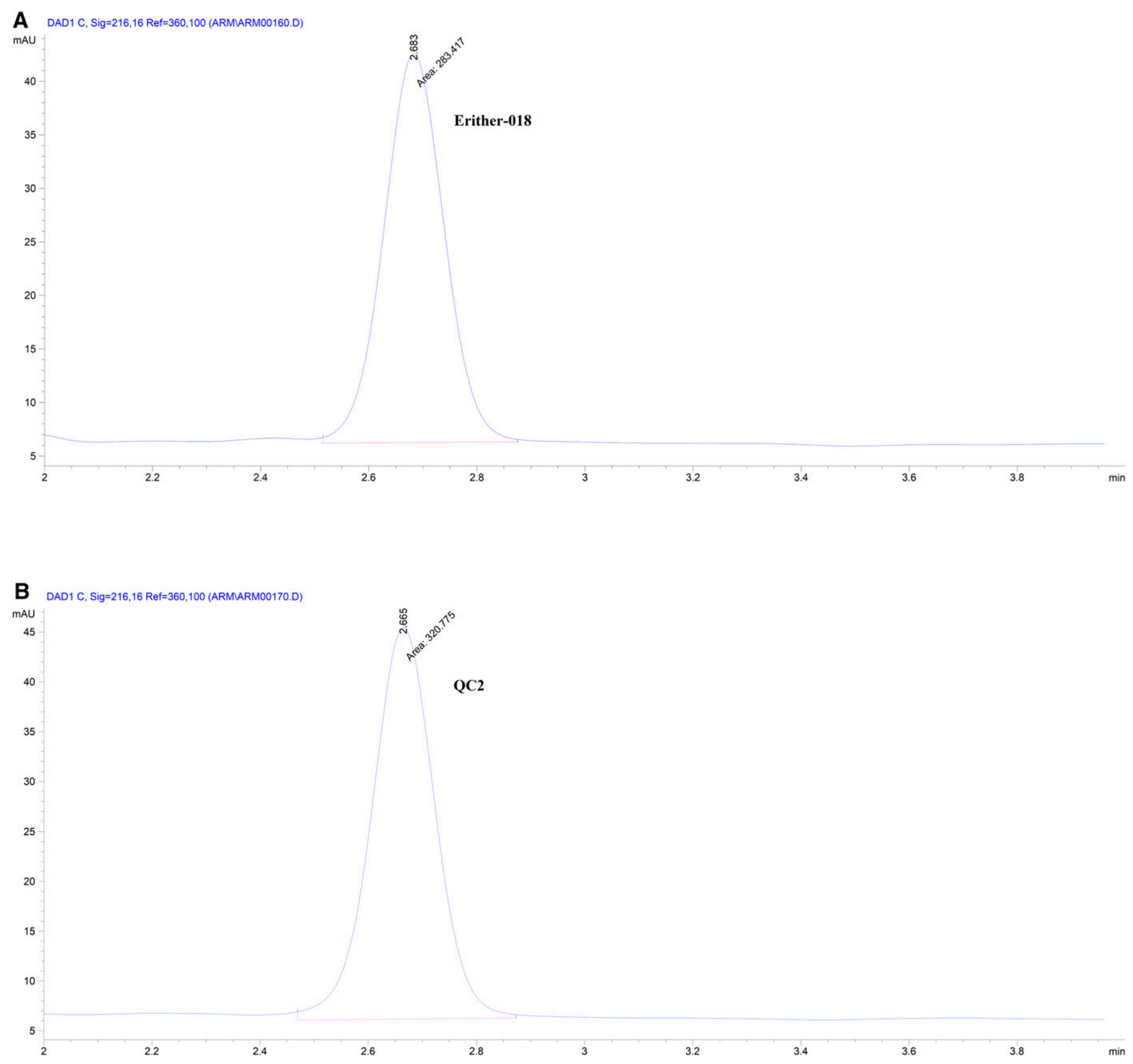

FIGURE 3. Chromatogram showing retention time for artemether. (A) A typical representative chromatogram for an investigated product and (B) a typical representative chromatogram for $800 \mu \mathrm{g} / \mathrm{mL}$ artemether reference standard. This figure appears in color at www.ajtmh.org.

time, more recrudescence, and emergence of resistance..$^{21-23}$ This becomes very crucial in the treatment of malaria, particularly when artemether is considered for severe malaria cases.

As earlier stated, many surveillance studies had reported on the quality of ACTs and other antimalarials in different locations and countries. Still, preference had always been given to oral formulations of antimalarials perhaps because of a more abundant sample availability. ${ }^{30-33}$ Only few studies had included artemether injection products in the samples surveyed, but these were not usually representative. ${ }^{44-46}$ To our knowledge, this study is the first to wholly investigate several samples (22) of artemether injection. Having considered the public health importance of antimalarial injection products, the present study has unveiled the need to subsequently include antimalarial injectables in prospective drug quality surveys. Our results agree with existing reports indicating a high prevalence of substandard products than the counterfeit products among the poor-quality medicines in Nigeria.

It is quite unfortunate that the problem of substandard drug proliferation still exists in Nigeria, regardless of the ongoing concerted effort of the drug regulatory agency. Substandard drugs may contain lesser than the stated amount of the active ingredient because of manufacturing errors or degradation of an adequately manufactured product within the logistic channel before reaching, and even at, the health service points where most sampling of drugs for post-marketing surveys are carried out. It is noteworthy that the location of this study (Southwest Nigeria) is of the tropical rainforest vegetation where an all year-round transmission of malaria takes place 
TABLE 3

HPLC assay of investigated samples

\begin{tabular}{|c|c|c|c|c|c|c|c|c|}
\hline $\mathrm{S} / \mathrm{N}$ & Product code & PA1 & $\mathrm{PA} 2$ & PA3 & A1 & $\mathrm{A} 2$ & $\mathrm{~A} 3$ & Mean \pm SD \\
\hline 1 & A001 & 317.3 & 293.9 & 295.6 & 836.93 & 775.96 & 780.39 & $797.76 \pm 27.76$ \\
\hline 2 & A002 & 291.6 & 290.6 & 291.6 & 769.97 & 767.36 & 769.97 & $769.10 \pm 1.23$ \\
\hline 3 & A003 & 220 & 242.8 & 248 & 583.41 & 642.82 & 656.37 & $627.53 \pm 31.68$ \\
\hline 4 & A004 & 258.4 & 256.2 & 262.5 & 683.47 & 677.73 & 694.15 & $685.12 \pm 6.80$ \\
\hline 5 & A005 & 291.5 & 286.7 & 281 & 769.71 & 757.20 & 742.35 & $756.42 \pm 11.18$ \\
\hline 6 & A006 & 283.5 & 288.7 & 291.2 & 748.86 & 762.41 & 768.93 & $760.07 \pm 8.36$ \\
\hline 7 & A007 & 256.2 & 253.1 & 253.3 & 677.73 & 669.66 & 670.18 & $672.52 \pm 3.69$ \\
\hline 8 & A008 & 238.8 & 230.2 & 236.6 & 632.40 & 609.99 & 626.67 & $623.02 \pm 9.50$ \\
\hline 9 & A009 & 247.1 & 243 & 251.6 & 654.02 & 643.34 & 665.75 & $654.37 \pm 9.15$ \\
\hline 10 & $\mathrm{~A} 010$ & 210.4 & 207.3 & 207.7 & 558.40 & 550.32 & 551.37 & $553.36 \pm 3.59$ \\
\hline 11 & A011 & 233.3 & 235.1 & 236.6 & 618.07 & 622.76 & 626.67 & $622.50 \pm 3.52$ \\
\hline 12 & $\mathrm{~A} 012$ & 273.3 & 271.6 & 272.6 & 722.29 & 717.86 & 720.46 & $720.20 \pm 1.82$ \\
\hline 13 & $\mathrm{~A} 013$ & 248.8 & 244.2 & 242.6 & 658.45 & 646.47 & 642.30 & $649.07 \pm 6.85$ \\
\hline 14 & $\mathrm{~A} 014$ & 269.8 & 286.5 & 281.8 & 713.17 & 756.68 & 744.44 & $738.10 \pm 18.32$ \\
\hline 15 & $\mathrm{~A} 015$ & 281.5 & 273.4 & 273.4 & 743.65 & 722.55 & 722.55 & $729.58 \pm 9.95$ \\
\hline 16 & A016 & 264.7 & 261.3 & 262.8 & 699.88 & 691.02 & 694.93 & $695.28 \pm 3.62$ \\
\hline 17 & A017 & 233 & 239.6 & 230.8 & 617.29 & 634.48 & 611.55 & $621.11 \pm 9.74$ \\
\hline 18 & A018 & 209.8 & 216.6 & 221.4 & 556.84 & 574.56 & 587.06 & $572.82 \pm 12.40$ \\
\hline 19 & A019 & 273.5 & 295.4 & 297.2 & 722.81 & 779.87 & 784.56 & $762.41 \pm 28.07$ \\
\hline 20 & A020 & 293.4 & 289.7 & 295.8 & 774.66 & 765.02 & 780.91 & $773.53 \pm 6.54$ \\
\hline 21 & A021 & 271.2 & 266.1 & 253.5 & 716.82 & 703.53 & 670.70 & $697.01 \pm 19.38$ \\
\hline 22 & A022 & 244.2 & 241.8 & 225.6 & 646.47 & 640.21 & 598.00 & $628.23 \pm 21.52$ \\
\hline 23 & ARM RS & 296.7 & 289.5 & 311.5 & 783.26 & 764.50 & 821.82 & $789.86 \pm 23.86$ \\
\hline
\end{tabular}

and which predisposes many individuals, especially the most vulnerable group, pregnant women, and children, to repeated malaria infection episodes in a year. In such a setting, like in many other regions of Nigeria, the importance of providing treatment with the right quality of medicines, especially parenteral drugs for severe malaria cases, cannot be overemphasized.

\section{CONCLUSION}

The findings of the study suggest that the proliferation of substandard antimalarial drugs persists in this malaria-endemic country. We recommend a more active prequalification program emphasizing the adequacy of the drug industry's quality assurance capacity, logistic systems for quality preservation,

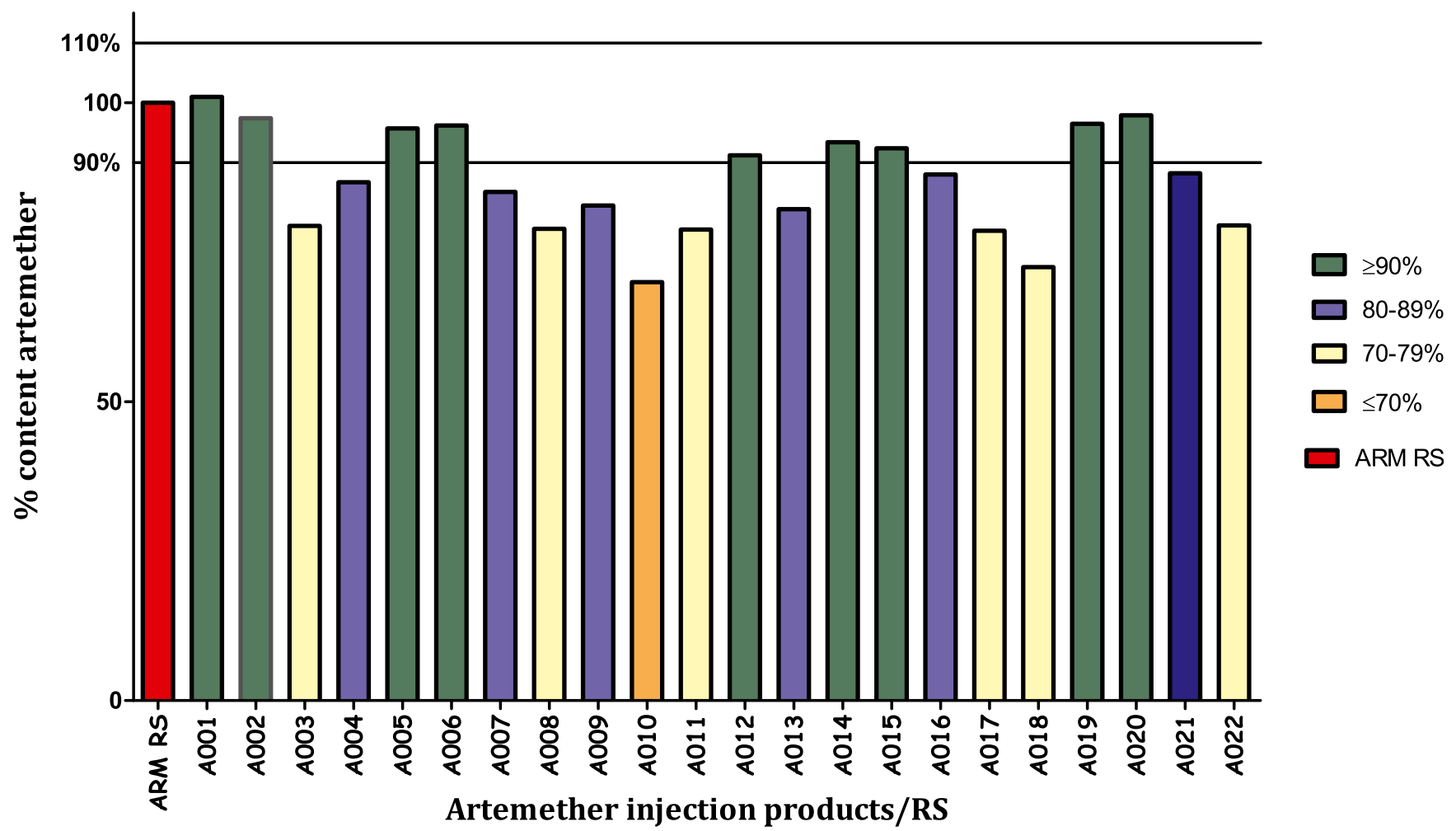

FIGURE 4. Bar chart showing the \% content of artemether in the investigated products. The International Pharmacopoeia specifies that artemether injection should contain not less than $90.0 \%$ and not more than $110.0 \%$. This figure appears in color at www.ajtmh.org. 
periodic surveillance to assess the quality of all antimalarial medicines, and improving the quality of the drug distribution system in Nigeria.

\section{LIMITATIONS OF THE STUDY}

The scope of the present study did not cover the microbiological quality evaluation and forensic analysis of trademarks, designs, and holograms of product samples. Besides, a convenience sampling technique was adopted, and only one geopolitical zone was included in this study of six geopolitical zones in Nigeria, suggesting similar studies are needed to cover more territories. However, the investigated brands of artemether injections were more than half $(58 \%)$ of the total brands in circulation in Nigeria.

Received March 13, 2020. Accepted for publication May 14, 2020.

Published online June 22, 2020.

Acknowledgments: We appreciate Amidat Hamid for providing technical assistance during sample collection and drug analysis. The American Society of Tropical Medicine and Hygiene (ASTMH) assisted with publication expenses.

Disclosure: The datasets used and analyzed during the current study are available from the corresponding author on reasonable request.

Authors'addresses: Ibrahim A. Hassan, Department of Pharmacy, Obafemi Awolowo University Teaching Hospital Complex, lle-lfe, Nigeria, E-mail: hadebayoibraheem@gmail.com. Adebanjo J. Adegbola, Department of Pharmaceutical Chemistry, Obafemi Awolowo University, lle Ife, Nigeria, E-mail: adegbolaaj@oauife.edu.ng. Julius O. Soyinka and Oluseye O. Bolaji, Department of Pharmaceutical Chemistry, Faculty of Pharmacy, Obafemi Awolowo University, Ile-Ife, Nigeria, E-mail: juliussoyinka@gmail.com and obolaji@oauife.edu.ng. Cyprian O. Onyeji, Department of Pharmaceutical Chemistry, Faculty of Pharmaceutical Sciences, University of Nigeria, Nssuka, Nigeria, E-mail: cyprian.onyeji@ unn.edu.ng.

\section{REFERENCES}

1. WHO, 2015. Guidelines for the Treatment of Malaria, 3rd edition. Geneva, Switzerland: World Health Organization, 30-45.

2. Romay-Barja M, Ncogo P, Nseng G, Santana-Morales MA, Berzosa P, Herrador Z, Valladares B, Riloha M, Benito A, 2018. The use and preference of artemether as a first-choice treatment for malaria: results from a cross-sectional survey in the Bata district, Equatorial Guinea. Malar J 17: 107.

3. Alonso S, Chaccour CJ, Elobolobo E, Nacima A, Candrinho B, Saifodine A, Saute F, Robertson M, Zulliger R, 2019. The economic burden of malaria on households and the health system in a high transmission district of Mozambique. Malar J 18: 360.

4. Kenangalem E et al., 2019. Malaria morbidity and mortality following introduction of a universal policy of artemisinin-based treatment for malaria in Papua, Indonesia: a longitudinal surveillance study. PLoS Med 16: e1002815.

5. WHO, 2019. World Malaria Report. Geneva, Switzerland: World Health Organization.

6. Okeke EU, 2012. Nigerian malaria: the problems and the fight. Malar J 11: 122.

7. Muhammad F, Abdulkareem JH, Chowdhury A, 2017. Major public health problems in Nigeria: a review. South East Asia $J$ Public Health 7: 6-11.

8. USAIDs, 2019. President's Malaria Initiative Nigeria; Malaria Operational Plan FY 2019. Atlanta, GA: Department of Health and Human Services, Centre for Disease Control and Prevention, and Department of States, United States of America.

9. Li Q, Weina P, 2010. Artesunate: the best drug in the treatment of severe and complicated malaria. Pharmaceuticals (Basel) 3: 2322-2332.

10. Esu EB, Effa EE, Opie ON, Meremikwu MM, 2019. Artemether for severe malaria. Cochrane Database Syst Rev 6: CD010678.
11. Pasvol G, 2006. The treatment of complicated and severe malaria. Br Med Bull 75-76: 29-47.

12. Kremsner PG et al., 2016. Intramuscular artesunate for severe malaria in African children: a multicenter randomized controlled trial. PLoS Med 13: e1001938.

13. Creek D, Bigira V, Arinaitwe E, Wanzira H, Kakuru A, Tappero J, Kamya MR, Dorsey G, Sandison TG, 2010. Increased risk of early vomiting among infants and young children treated with dihydroartemisinin-piperaquine compared with artemetherlumefantrine for uncomplicated malaria. Am J Trop Med Hyg 83: 873-875.

14. Bartoloni A, Zammarchi L, 2012. Clinical aspects of uncomplicated and severe malaria. Mediterr J Hematol Infect Dis 4: e2012026.

15. Silamut K, Newton PN, Teja-Isavadharm P, Suputtamongkol $Y$, Siriyanonda D, Rasameesoraj M, Pukrittayakamee S, White NJ, 2003. Artemether bioavailability after oral or intramuscular administration in uncomplicated falciparum malaria. Antimicrob Agents Chemother 47: 3795-3798.

16. Deen JL, von Seidlein L, Dondorp AM, 2008. Therapy of uncomplicated malaria in children: a review of treatment principles, essential drugs and current recommendations. Trop Med Int Health 13: 1111-1130.

17. Bruxvoort K, Goodman C, Kachur SP, Schellenberg D, 2014. How patients take malaria treatment: a systematic review of the literature on adherence to antimalarial drugs. PLoS One 9: e84555.

18. Burrows JN, Hooft van Huijsduijnen R, Möhrle JJ, Oeuvray C, Wells TNC, 2013. Designing the next generation of medicines for malaria control and eradication. Malar J 12: 187.

19. The mal ERACGoD, 2011. A research agenda for malaria eradication: drugs. PLoS Med 8: e1000402.

20. Ozawa S, Evans DR, Bessias S, Haynie DG, Yemeke TT, Laing SK, Herrington JE, 2018. Prevalence and estimated economic burden of substandard and falsified medicines in low- and middle-income countries: a systematic review and meta-analysis. JAMA Network Open 1: e181662.

21. Ozawa S, Haynie D, Bessias S, Laing S, Ngamasana EL, Yemeke TT, Evans DR, 2019. Modeling the economic impact of substandard and falsified antimalarials in the Democratic Republic of the Congo. Am J Trop Med Hyg 100: 1149-1157.

22. Beargie SM, Higgins CR, Evans DR, Laing SK, Erim D, Ozawa S, 2019. The economic impact of substandard and falsified antimalarial medications in Nigeria. PLoS One 14: e0217910.

23. Barton I, Avanceña ALV, Gounden N, Anupindi R, 2019. Unintended consequences and hidden obstacles in medicine access in sub-Saharan Africa. Front Public Health 7: 342.

24. Nayyar GML, Breman JG, Mackey TK, Clark JP, Hajjou M, Littrell $\mathrm{M}$, Herrington JE, 2019. Falsified and substandard drugs: stopping the pandemic. Am J Trop Med Hyg 100: 1058-1065.

25. Haijou $\mathrm{M}$ et al., 2015. Monitoring the quality of medicines: results from Africa, Asia, and South America. Am J Trop Med Hyg 92: 68-74.

26. HC3, U-FHCCC, 2016. Landscape of Antimalarial Medicines in Nigeria. Baltimore, MD: Johns Hopkins Center for Communication Programs.

27. WHO, 2017. Global Surveillance and Monitoring System for Substandard and Falsified Medical Products. Geneva, Switzerland: World Health Organization.

28. Newton PN et al., 2009. Guidelines for field surveys of the quality of medicines: a proposal. PLoS Med 6: e1000052.

29. Onwujekwe O, Kaur H, Dike N, Shu E, Uzochukwu B, Hanson K, Okoye V, Okonkwo P, 2009. Quality of anti-malarial drugs provided by public and private healthcare providers in southeast Nigeria. Malar J 8: 22.

30. Kaur H et al., 2015. Quality of artemisinin-based combination formulations for malaria treatment: prevalence and risk factors for poor quality medicines in public facilities and private sector drug outlets in Enugu, Nigeria. PLoS One 10: e0125577.

31. Mgbahurike AA, Azike NR, Ukweze SE, 2017. Assessment of quality of commercially available artemether-lumefantrine tablets in Rivers state, Nigeria. World J Pharm Res 6: 274-290.

32. Izevbekhai O, Adeagbo B, Olagunju A, Bolaji O, 2017. Quality of artemisinin-based antimalarial drugs marketed in Nigeria. Trans $R$ Soc Trop Med Hyg 111: 90-96. 
33. Adeyemi D, Ogochukwu S, Johnson O, Akinleye M, 2018. Quality assessment of twenty brands of sulfadoxine-pyrimethamine tablets marketed in Mainland. J Chem Soc Nigeria 43: 81-89.

34. Joda A, Amadi C, Adebayo O, Maji Y, Uchem C, Olih H, 2017. Fake drugs: a survey of healthcare providers in Lagos state, Nigeria. Niger J Basic Clin Sci 14: 137-142.

35. Nations U, 2019. World Population Prospects (2019 Revision) United Nations Population Estimates and projections. Total Population: Estimated to Be Consistent with the 1963, 1991 and 2006 Censuses, Adjusted for Underenumeration, with the Age and Sex Structure from the 2011 MICS4 Survey, and with Estimates of the Subsequent the Trends in Fertility, Mortality and International Migration. New York, NY: Department of Economic and Social AffairsPopulation Dynamics.

36. Faleyimu OI, Agbeja BO, 2012. Constraints to forest policy implementation in the southwest Nigeria: causes, consequences and cure. Resour Environ 2: 37-44.

37. Daniel WW, 1999. Biostatistics: A Foundation for Analysis in the Health Sciences. New York, NY: John Wiley \& Sons.

38. WHO, 2019. Artemether injection monograph. The International Pharmacopoeia. Geneva, Switzerland: World Health Organization.

39. Centre for Drug Evaluation and Research (CDER), 2018. Bioanalytical Method Validation Guidance for Industry. Silver Spring, MD: US Food and Drug Administration.

40. Adegbolagun OM, Adesuyi OA, Emikpe BO, Awelewa BE, Ogunremi Y, 2016. Dihydroartemisinin photoirradiation: reduced antiplasmodic activity and toxicological implications. Afr J Biomed Res 19: 89-97.

41. FDA, 2015. Allowable Excess Volume and Labeled Vial Fill Size in Injectable Drug and Biological Products; Guidance for Industry. Silver Spring, MD: U.S. Department of Health and Human Services, Food and Drug Administration, Center for Drug Evaluation and Research (CDER). Center for Biologics Evaluation and Research (CBER).

42. Rosenthal PJ, 2018. Artemisinin resistance outside of Southeast Asia. Am J Trop Med Hyg 99: 1357-1359.

43. Ouji M, Augereau JM, Paloque L, Benoit-Vical F, 2018. Plasmodium falciparum resistance to artemisinin-based combination therapies: a sword of Damocles in the path toward malaria elimination. Parasite 25: 24.

44. Osei-Safo D, Agbonon A, Konadu DY, Harrison JJEK, Edoh M, Gordon A, Gbeassor M, Addae-Mensah I, 2014. Evaluation of the quality of artemisinin-based antimalarial medicines distributed in Ghana and Togo. Malar Res Treat 2014: 806416.

45. El-Duah M, Ofori-Kwakye K, 2012. Substandard artemisininbased antimalarial medicines in licensed retail pharmaceutical outlets in Ghana. J Vector Borne Dis 49: 131-139.

46. Prah J, Ameyaw EO, Afoakwah R, Fiawoyife P, Oppong-Danquah E, Boampong JN, 2016. Quality assessment of artemetherlumefantrine samples and artemether injections sold in the cape coast metropolis. J Trop Med 2016: 8602619. 